\title{
The effect of a copolymer inhibitor on baryte precipitation
}

\author{
Cristina Ruiz-Agudo*, Christine V. Putnis and Andrew Putnis \\ Institut für Mineralogie, University of Münster, 48149 Münster, Germany
}

[Received 6 May 2014; Accepted 6 November 2014; Associate Editor: T. Stawski]

\section{ABSTRACT}

In situ atomic force microscopy (AFM) experiments were used to study the effect of trace amounts of a commercial inhibitor on the (001) baryte surface during growth. The additive tested was a copolymer, used as a scale inhibitor in oil recovery (maleic acid/allyl sulfonic acid copolymer with phosphonate groups, partial sodium salt). The morphology of the growth was used to gain a better understanding of the inhibition mechanism. Without an inhibitor, barium sulfate growth occurred by $2 \mathrm{D}$ island nucleation and spreading. The addition of a small amount $(0.1 \mathrm{ppm}$ and $0.5 \mathrm{ppm})$ of copolymer inhibitor enhances 2D nucleation but blocks growth. Just $1 \mathrm{ppm}$ of inhibitor blocks nucleation and growth by adsorption of a copolymer layer onto the baryte surface. Similarly in 3D studies, small amounts of inhibitor seem to act on growth and not on nucleation and larger amounts of copolymer act on both by adsorption of the copolymer to all baryte surfaces keeping the particles in their embryo stage.

KeYwords: AFM, baryte, scale inhibitor.

\section{Introduction}

PRECIPITATION of baryte $\left(\mathrm{BaSO}_{4}\right)$ causes major problems in numerous industrial processes such as paper-making, chemical manufacturing, cement operations, off-shore oil extraction and geothermal energy production (Sorbie and Mackay, 2000). In oil recovery, baryte scale forms as a result of the mixing of two waters of different compositions: injection water (mainly seawater) and formation water (water in the pores of the reservoir rock). This combination allows the mixing of $\mathrm{SO}_{4}$ from the seawater and $\mathrm{Ba}$ in the pore water, producing a supersaturation with respect to $\mathrm{BaSO}_{4}$. Because of its low solubility $\left(\log K_{\mathrm{sp}}=-9.96\left(25^{\circ}\right)\right.$ (Blount, 1977), solid layers of baryte form in the oil pipes and the reservoir rocks, reducing permeability in the reservoir and eventually reducing or even stopping the production of an oil well. Due to the difficulty in removing these scales, it is important to study strategies for preventing the deposition of baryte

* E-mail: c_ruiz02@uni-muenster.de

DOI: $10.11 \overline{8} 0 /$ minmag.2014.078.6.09 or for modifying the morphology of the precipitate in order to avoid the deposition of a hard crust of barium sulfate scale.

The most appropriate strategy used to reduce or to retard scale formation is the addition of trace amounts of scale inhibitors (usually phosphonates or carboxylates) to the water injected into the reservoir (threshold treatment, Shakkthivel et al., 2006). The amount of these organic compounds added to the solution is generally not sufficient to complex metal ions and reduce the supersaturation. Most synthetic commercial additives contain the same functional groups, e.g. carboxylic acid $(\mathrm{COOH})$, phosphonic acids $\left(\mathrm{PO}_{3} \mathrm{H}_{2}\right)$ and sulfonic acids $\left(\mathrm{SO}_{3} \mathrm{H}\right)$. These organic additives can act as inhibitors or promoters of crystallization (Benton et al., 1993).

In threshold treatments, inhibitors are assumed to act by blocking active growth sites through

This paper is published as part of a special issue in Mineralogical Magazine, Vol. 78(6), 2014 entitled 'Mineral-fluid interactions: scaling, surface reactivity and natural systems'. 
adsorption to the crystal surface (Van der Leeden and Van Rosmalen, 1995). These growth inhibitors retard crystal growth and most of them introduce morphological changes in the crystal. They can stop scale formation in systems in which there are seed crystals and in systems in which nucleation has not yet occurred (Van Rosmalen, 1983). Despite the extensive research performed on this topic, there is still a lack of understanding of the exact mechanism by which these inhibitors modify crystal growth. The inhibitor molecules are thought to be adsorbed on specific crystal surfaces and hinder growth by blocking the active sites at the surface (Sangwal, 1998), but direct evidence of this mechanism is, in general, absent. In the present study, the mechanism by which this commercial copolymer acts as an inhibitor in the formation of barium sulfate was examined. With this purpose, atomic force microscopy (AFM), conductivity measurements and scanning electron microscopy (SEM) were used to gain a better understanding of baryte precipitation in the presence of this specific inhibitor. Previous studies of baryte-growth inhibition with commercial copolymers have been carried out (e.g. Fernández-Díaz et al., 1990; Mavredaki et al., 2011a,b; Qi et al., 2000) but not combining the same techniques as being used in the present study, to our knowledge.

Atomic force microscopy allows us to study "in tempore" and "in situ" the effect of inhibitors on crystal growth at a nano-scale. Surfaces can be observed during growth and this makes it possible to improve our understanding of the molecular mechanism controlling the inhibition (e.g. Pina et al., 2004). Trace amounts of a commercial inhibitor were tested in AFM flow-through experiments using cleaved (001) surfaces of baryte crystals as substrates.

Conductivity was monitored during the baryte precipitation process to determine the efficiency of increasing concentration of this commercial inhibitor. Scanning electron microscopy (SEM) observations of baryte particles obtained from conductivity experiments allowed us to study changes in morphology and in the number of particles precipitated.

\section{Experimental details}

\section{AFM in situ experiments}

The AFM flow-through experiments were performed at room temperature $\left(20 \pm 2^{\circ} \mathrm{C}\right)$ in a fluid cell of a Digital Instruments (Bruker)
Multimode Nanoscope IIIa AFM, working in contact mode. Optically clear baryte single crystals from Arran (Scotland) were used as substrates in the experiments. The crystals were cleaved immediately before each experiment to obtain fresh (001) surfaces. At the beginning of each experiment, deionized water (Milli-Q, resistivity $>18.2 \mathrm{M} \Omega \mathrm{cm}$ ) was passed over the crystal to adjust the AFM parameters and eliminate any fine particles. Growth solutions of $50 \mu \mathrm{M}$ concentration were prepared from $1 \mathrm{M}$ stock solutions of $\mathrm{BaCl}_{2}$ and $\mathrm{Na}_{2} \mathrm{SO}_{4}$ (made from solids from Merck Suprapur min. 99.995\% $\left(\mathrm{BaCl}_{2}\right)$ and Aldrich min. $99 \%\left(\mathrm{Na}_{2} \mathrm{SO}_{4}\right)$ and deionized water (Milli-Q, resistivity $>18.2 \mathrm{M} \Omega \mathrm{cm})$. The PHREEQC computer program (Parkhurst and Appelo, 1999) was used to calculate molarities and supersaturation states. The solutions were injected into the fluid cell before each AFM scan, giving a flow rate of $\sim 80 \mathrm{ml} / \mathrm{h}$. Previous results suggest that, under such flow conditions, the growth is surface controlled rather than the diffusion controlled (Teng et al., 1998). Images were recorded continuously.

An aqueous solution of a commercial inhibitor (maleic acid/allyl sulfonic acid copolymer with phosphonate groups, partial sodium salt) was mixed with the growth solution (equimolar $\mathrm{Na}_{2} \mathrm{SO}_{4}$ and $\mathrm{BaCl}_{2}$ ) immediately prior to each experiment. This inhibitor is used to reduce baryte scale in oil production in the North Sea oil fields. Just one concentration of $\mathrm{BaSO}_{4}$ was tested in this study $(50 \mu \mathrm{M})$ and three concentrations of the inhibitor in the growth solutions, $0.25 \mathrm{ppm}$, $0.5 \mathrm{ppm}$ and $1 \mathrm{ppm}$.

In all the experiments, growth solution was injected first without inhibitor to assess growth development on the surface in the absence of inhibitor, as growth on baryte is strongly dependent on surface reactivity (Kowacz et al., 2007). Note that the results observed on the (001) surface do not necessarily relate to the crystal as a whole.

\section{Conductivity experiments}

Unseeded conductivity experiments were carried out to determine the rate of change in conductivity during precipitation of barium sulfate. The graph of conductivity vs. time was used to calculate the precipitation rate by fitting the linear region of the curve (Jones et al., 2002). These precipitation experiments were carried out 
at controlled temperature $\left(20^{\circ} \mathrm{C}\right)$ in a jacketed reaction vessel. A conductivity-meter $(905$ Titrando, Metrohm) was used to monitor the evolution of conductivity and $\mathrm{pH}$ in situ. The natural measured $\mathrm{pH}$ was 5.5-6.0. A magnetic stirrer was used to keep the solids in suspension. The method consisted of adding $25 \mu \mathrm{l}$ of $1 \mathrm{~m}$ $\mathrm{BaCl}_{2}$ solution to $100 \mathrm{ml}$ of $0.25 \mathrm{mM} \mathrm{Na}_{2} \mathrm{SO}_{4}$ (with the corresponding tested amount of inhibitor added to the sodium sulfate solution: $0.25,0.5,1$ and $2 \mathrm{ppm}$ ).

After the conductivity experiments, the solutions were filtered through cellulose nitrate membrane filters (Millipore pore size $=$ $0.45 \mu \mathrm{m}$ ) and baryte particles were dried at $40^{\circ} \mathrm{C}$ for $24 \mathrm{~h}$ before carbon coating prior to analysis by field emission SEM (Auriga Carl Zeiss SMT) equipped with Energy Dispersive X-ray analysis (EDX), which allowed the precipitated particles to be characterized.

\section{Results}

\section{AFM experiments}

When the $50 \mu \mathrm{m}$ barium sulfate growth solution (Saturation Index, SI $=1.30$, where SI $=\log \Omega$, and $\left.\Omega=a\left(\mathrm{Ba}^{2+}\right) * a\left(\mathrm{SO}_{4}^{2-}\right) / K_{\mathrm{sp}}\right)$ with no inhibitor was injected into the fluid cell, $2 \mathrm{D}$ island nucleation and spreading on the (001) baryte surface was the growth mechanism observed. The characteristic sector shape of two-dimensional (2D) nuclei with two straight sides and a curved side forming an obtuse angle $\left(\sim 100^{\circ}\right)$ at the apex of the sector (Pina et al., 1998) is seen in Fig. 1a,e,i. While injecting the growth solution into the AFM fluid cell, 2D islands could be observed nucleating, growing and merging together to form a new layer, while new nuclei formed on top of this layer and the process repeated. The height of the $2 \mathrm{D}$ islands was $\sim 3.5 \AA$, corresponding to half a unit cell of baryte.

When $0.1 \mathrm{ppm}$ of inhibitor was added to the $50 \mu \mathrm{M}$ growth solution, 2D nucleation was immediately enhanced significantly over the first $90 \mathrm{~s}$ (Fig. 1b). However, these 2D nuclei did not seem to grow. After three scans ( $270 \mathrm{~s})$, while injecting this solution, the surface was covered by a rough layer (Fig. 1c) that made any further observation of surface growth difficult. After injecting this solution for $900 \mathrm{~s}, 50 \mu \mathrm{M}$ growth solution (without inhibitor) was again added and after $\sim 360 \mathrm{~s}$ injecting solution, normal growth was recovered and the surface no longer had a rough appearance (Fig. 1d).
With $0.5 \mathrm{ppm}$ of inhibitor in the growth solution, the same effect of enhanced nucleation on the surface was first observed (Fig. 1f). Approximately $1260 \mathrm{~s}$ after injecting this solution, the whole surface was covered with rounded nmsized particles of $\sim 50-150 \mathrm{~nm}$ in diameter (Fig. $1 g$ ). When a larger area of $8 \mu \mathrm{m} \times 8 \mu \mathrm{m}$ was scanned, the rounded particles were clearly seen to be concentrated in the area in which the AFM tip was scanning and not on the rest of the surface (Fig. 1h).

When $1 \mathrm{ppm}$ of inhibitor was added to the growth solution, limited growth of the preexisting islands was observed only during the first scan (90 s) (Fig. 1j). After the first scan, and continuous injection of the same solution $(50 \mu \mathrm{M}$ $\mathrm{BaSO}_{4}+1 \mathrm{ppm}$ inhibitor) for $1500 \mathrm{~s}$, no further nucleation or growth was detected. Black circles in Fig. $1 j$ and $1 k$ show islands that did not grow after the injection of inhibitor solution and yellow squares mark pre-existing spaces between islands, which did not close as a result of the growth arrest. After this first $1500 \mathrm{~s}$ with no growth on the surface, the original growth solution without inhibitor $\left(50 \mu \mathrm{M} \mathrm{BaSO}_{4}\right)$ was injected in an attempt to recover growth. This inhibitor-free growth solution, that previously gave immediate nucleation and fast growth when it was first passed over the cleaved baryte surface, produced neither new nuclei nor growth of the pre-existing islands in a further $1500 \mathrm{~s}$. The same original islands could easily be identified and they remained the same size and shape. Interestingly, the small rounded shapes seen when $0.5 \mathrm{ppm}$ of inhibitor was tested appeared again but fewer than previously (green circles in Fig. 1l).

Raman spectroscopy analysis carried out after the AFM experiments detected only baryte. Attempts to identify the precipitate failed, probably due to the thinness of this layer.

\section{Conductivity measurements}

The results of monitoring conductivity during the precipitation process of barium sulfate in the presence of different trace amounts of inhibitor are shown in Fig. 2. The rate of change in conductivity in the linear regime of the curves was used as an indicator of the effectiveness of different amounts of inhibitor compared to the control average change in conductivity. In Fig. 2, next to each conductivity curve (corresponding to a different amount of inhibitor), the average value 

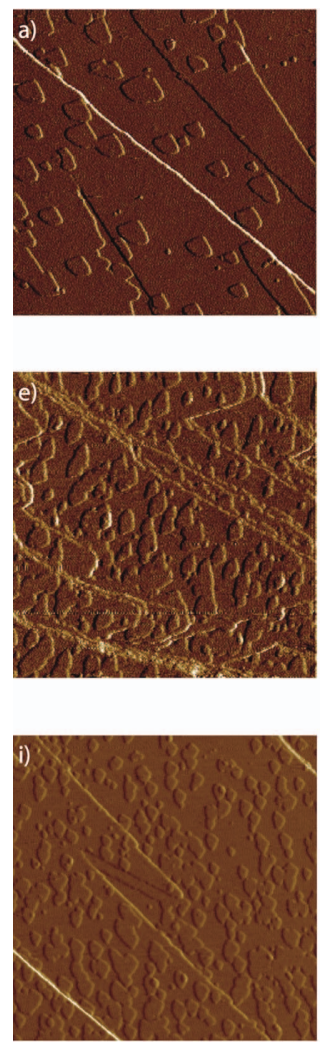

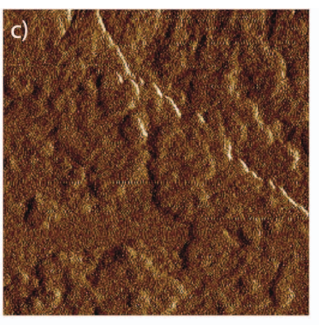

$0.1 \mathrm{ppm}$ inhibitor
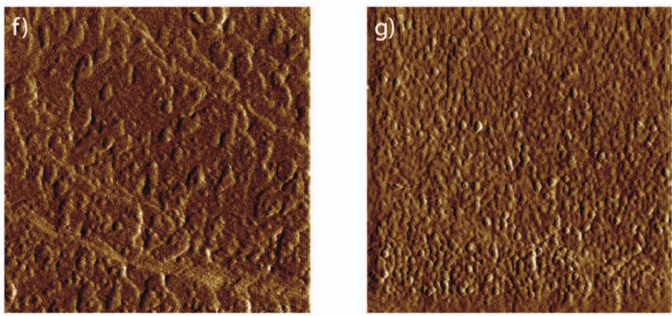

0.5 ppm inhibitor
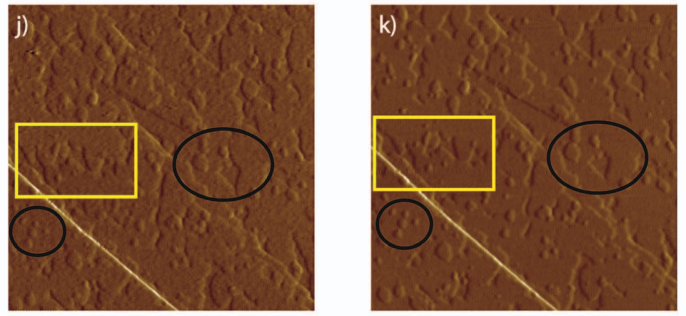

1 ppm inhibitor
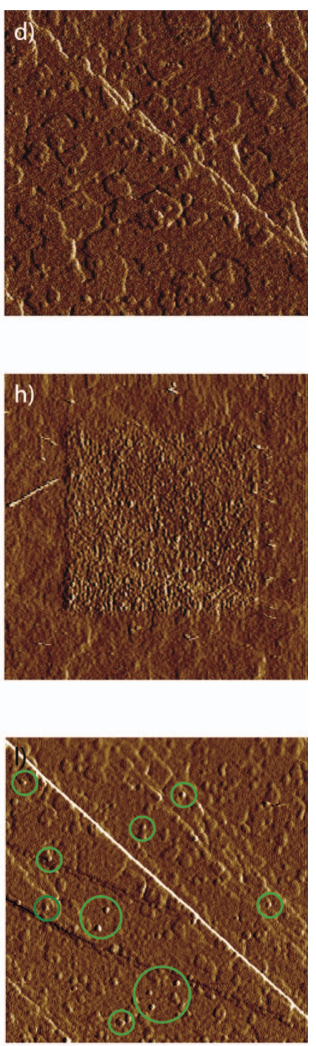

FIG. 1. AFM deflection images $(5 \mu \mathrm{m} \times 5 \mu \mathrm{m})$ of growth on (001) cleaved baryte surfaces: $(a) 360 \mathrm{~s}$ after injection of growth solution $(50 \mu \mathrm{M})$ without inhibitor; $(b) 90 \mathrm{~s}$ after injection of growth solution $(50 \mu \mathrm{M})+0.1 \mathrm{ppm}$ inhibitor; (c) $1260 \mathrm{~s}$ after injection of growth solution $(50 \mu \mathrm{M})+0.1 \mathrm{ppm}$ inhibitor $(2 \mu \mathrm{m} \times 2 \mu \mathrm{m})$; $(d) 360 \mathrm{~s}$ after injection of growth solution again $(50 \mu \mathrm{M})$; growth was recovered and surface was clearer. $(e) 360 \mathrm{~s}$ after injection of growth solution $(50 \mu \mathrm{M})$ without inhibitor; $(f) 90 \mathrm{~s}$ after injection of growth solution $(50 \mu \mathrm{M})+0.5 \mathrm{ppm}$ inhibitor; $(g) 1260 \mathrm{~s}$ after injection of growth solution $(50 \mu \mathrm{M})+0.5 \mathrm{ppm}$ inhibitor; $(h) 1350 \mathrm{~s}$ after injection of growth solution $(50 \mu \mathrm{M})+$ $0.5 \mathrm{ppm}$ inhibitor $(8 \mu \mathrm{m} \times 8 \mu \mathrm{m})$; $(i) 270 \mathrm{~s}$ after injection of growth solution $(50 \mu \mathrm{M})$ without inhibitor; $(j) 90 \mathrm{~s}$ after injection of growth solution $(50 \mu \mathrm{M})+1 \mathrm{ppm}$ inhibitor; $(k) 1500 \mathrm{~s}$ after injection of growth solution $(50 \mu \mathrm{M})+1 \mathrm{ppm}$ inhibitor; $(l) 1500 \mathrm{~s}$ after injection of growth solution again $(50 \mu \mathrm{M})$, with no inhibitor. Black circles in parts $j$ and $k$ show islands that did not grow after the injection of inhibitor solution and yellow squares in parts $j$ and $k$ mark preexisting spaces between islands that did not close as a result of the growth arrest. Green circles in part $l$ point to the small, rounded particles obtained.

$(\%)$ of effectiveness of the corresponding amount of inhibitor is presented. For the control run the average slope of the precipitation curve was $(-9.1903 \pm 1.3875) \times 10^{-5} \mathrm{mS} \mathrm{cm}^{-1} \mathrm{~s}^{-1}$. The reproducibility of the control runs was tested before each different amount of inhibitor. The values of effectiveness for $0.25,0.5,1$ and $2 \mathrm{ppm}$ were 18, 87, 93 and 96\%, respectively. The difference in inhibitor capacity between 1 and $2 \mathrm{ppm}$ was small even when the amount of inhibitor was doubled.
The induction time was determined from the intersection between the tangent to the initial conductivity value and the line corresponding to the linear regime of the conductivity curve. Average representative induction times were difficult to obtain from conductivity or $\mathrm{pH}$ measurements due to small differences in induction times. Nevertheless, a general trend of increasing induction time with increasing inhibitor concentration up to $0.5 \mathrm{ppm}$ can be deduced from our measurements (see Fig. 2, right corner). 


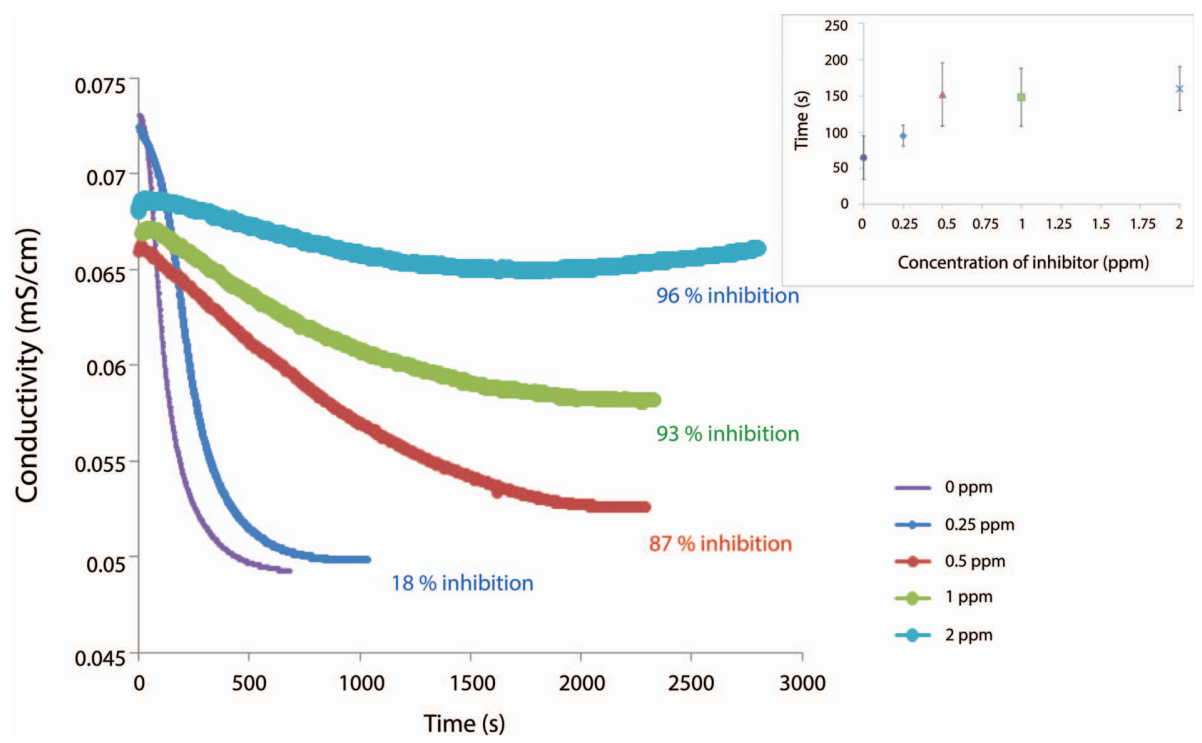

Fig. 2. Representative curves obtained from conductivity experiments. Specific conductance $(\mathrm{mS} / \mathrm{cm})$ was monitored $v s$. time. The slope of the conductivity curve in the linear regime is related to the precipitation rate and was used to obtain the effectiveness of different amounts of copolymer. Inset: values of induction time vs. copolymer concentration are plotted.

With increasing amount of inhibitor for 1 and $2 \mathrm{ppm}$, variation in the induction time compared with $0.5 \mathrm{ppm}$ was noted.

\section{D morphology of barium sulfate particles}

The morphologies of baryte particles collected after the conductivity experiments are shown in Fig. 3. Control precipitates (formed in the absence of inhibitor) have typical rectangular, pillow shapes reported by other authors (e.g. Jones et al., 2002), with an homogeneous size distribution and an average size of $4 \mu \mathrm{m} \times 2 \mu \mathrm{m}$. When $0.25 \mathrm{ppm}$ of inhibitor was added to the growth solution, the shape of the particles was not modified but single crystals tended to form aggregates, and the average size of the individual crystals decreased to $\sim 500 \mathrm{~nm} \times 250 \mathrm{~nm}$ (Fig. $3 a$ ). These particles do not look smooth on the surface like the control particles obtained without inhibitor, but present a rough surface with a 'layer' attached on different faces of the baryte precipitates. The baryte particles are around eight times smaller and the number of particles obtained was greater than the number achieved when grown in the absence of inhibitor.

An increase in the amount of inhibitor in the solution $(0.5 \mathrm{ppm})$ resulted in the formation of large aggregates of particles that individually mostly retain the pillow shape $(300 \mathrm{~nm} \times 200 \mathrm{~nm})$ (Fig. 3b). Some aggregates also began to exhibit rounded and irregular shapes at this concentration of inhibitor.

In the presence of 1 and $2 \mathrm{ppm}$ inhibitor, the shape of the baryte particles changed dramatically (Fig. 3c). The rectangular, pillow-shaped crystals began to appear as aggregates of rounded particles with a diameter ranging from 50 to $150 \mathrm{~nm}$.

No differences in EDX analysis between control particles and particles obtained in the presence of the inhibitor were detected. To detect any incorporation of inhibitor into the precipitated particles, further analysis is required, but was beyond the scope of the present work.

\section{Discussion}

The AFM observations show that growth from a $50 \mu \mathrm{M} \mathrm{BaSO}{ }_{4}$ additive-free growth solution occurs by $2 \mathrm{D}$ nucleation of sector-shaped islands on the (001) surface of a cleaved baryte crystal. The islands grew and merged together to form a new growth layer and new islands nucleate on top to eventually join to form another layer. The addition of trace amounts of a commercial copolymer to the $50 \mu \mathrm{M} \mathrm{BaSO}_{4}$ solution, modified substantially 

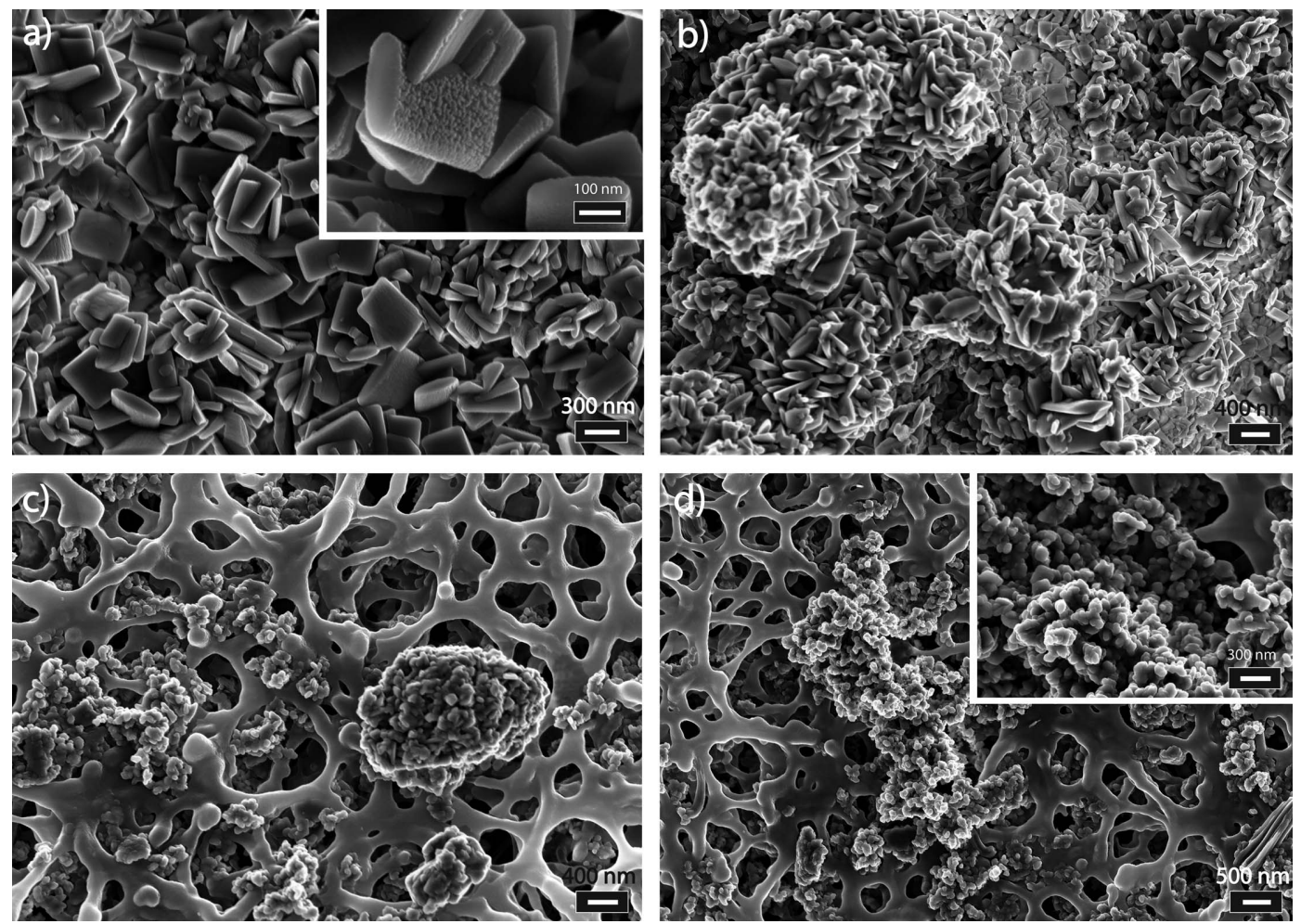

FIG. 3. FESEM images of barium sulfate particles obtained after conductivity experiments in the presence of commercial inhibitor. The concentration of barium sulfate was $250 \mu \mathrm{M}$ in all the experiments: $(a)+0.25 \mathrm{ppm}$ inhibitor; $(b)+0.5 \mathrm{ppm}$ inhibitor; $(c)+1 \mathrm{ppm}$ inhibitor; $(d)+2 \mathrm{ppm}$ inhibitor. Note the growth modifications occurring with increasing amounts of copolymer inhibitor.

surface growth on the (001) baryte face. Small amounts of inhibitor $(0.1 \mathrm{ppm}$ and $0.5 \mathrm{ppm})$ enhanced 2D nucleation immediately. This enhancement of 2D nucleation was previously observed by Baynton et al. (2011) for baryte in the presence of other organic molecules, (BTR 14 benzene-1,3,5-triphosphonic acid) and (BTS 14 benzene-1,3,5-trisulfonic acid) and in the presence of two calixarene molecules (Baynton et al., 2012). Those authors suggested that this is due to changes in the dehydration of barium ions, which has been shown to be the barrier for barium sulfate crystallization (Piana et al., 2006). They also suggested that there is a binding between the organic anion and barium and if this is relatively weak it would aid crystallization. The present results are in agreement with this hypothesis. The copolymer used in the present experiments contains both sulfonic and phosphonate groups similar to the inhibitors studied by Baynton et al. (2011).
When $0.5 \mathrm{ppm}$ of inhibitor was tested, as mentioned above, 2D nucleation was enhanced in the first $350 \mathrm{~s}$ but after $\sim 500 \mathrm{~s}$ the growth mechanism changed. Instead of $2 \mathrm{D}$ island nucleation and spreading, rounded nanoparticles $(50-150 \mathrm{~nm})$ appeared on the surface and attached only to the area in which the AFM tip was scanning. This might be due to the stabilization of baryte nanoparticles by the copolymer and later attached to the surface. The attachment just in the area in which the AFM tip was scanning can be due to the removal of a previously deposited layer of inhibitor. Similar observations have been reported by Long et al. (2013) for $\mathrm{CaCO}_{3}$ precipitation in the presence of polyacrylic acid (PAA).

With the addition of $1 \mathrm{ppm}$ of the commercial copolymer to the growth solution, no further growth was observed. New islands were not observed to develop on the surface, and those existing at the 
surface were 'frozen' or inhibited from further growth during the period of time $(\sim 1000 \mathrm{~s})$ during which the solution was injected continuously through the fluid cell. When the concentration of inhibitor was greater $(1 \mathrm{ppm})$ the inhibitory effect of the copolymer would possibly become dominant compared to the effect on barium de-hydration. The failed attempt to recover growth upon the reinjection of $50 \mu \mathrm{m}$ of additive-free baryte growth solution suggests the existence of an inhibitor layer deposited on the (001) baryte surface, preventing nucleation or growth. Passivation of the baryte (001) surface has already been observed by Putnis et al. (2008) when they studied the effect of commercial chelators on the dissolution of $\mathrm{BaSO}_{4}$. In their study, a soft layer of a precipitate covered the baryte (001) surface hindering the dissolution process. Pina et al. (2004) also studied the influence of various phosphonate inhibitors on baryte growth, observed in AFM, and reported the changes in normal island growth on a baryte surface in the presence of inhibitors.

As can be seen from the conductivity measurements in the present study, an increase in the amount of inhibitor resulted in enhanced inhibition. Representative values of induction times were difficult to obtain, as no large differences were observed under the experimental conditions, suggesting that at low concentration (up to $0.5 \mathrm{ppm}$ ) the inhibitor probably acts more as a growth inhibitor than a nucleation inhibitor. The density of particles found with 0.25 ppm (Fig. $3 a$ ) and $0.5 \mathrm{ppm}$ (Fig. $3 b$ ) do not exhibit a clear 3D-nucleation inhibitor effect.

The presence of inhibitor introduces major changes in the size and morphology of baryte particles. The crystal habit of baryte changes from rectangular-shaped forms in the presence of $0.25 \mathrm{ppm}$ (Fig. $3 a$ ) to baryte aggregates of pillow-shaped particles with 0.5 ppm (Fig. $3 b$ ) and finally to aggregates of rounded nanometer particles with 1 and $2 \mathrm{ppm}$ (Fig. $3 c, d$ ). The rounded forms obtained with increasing amounts of inhibitor are strong evidence of inhibitor molecules adsorbed to all baryte surfaces acting as a 'universal face binding agent'. These rounded particles are quite clearly the result of a loss of faceting of single crystals (Coveney et al., 2000).

The size of the particles has also been reduced to $50-150 \mathrm{~nm}$ indicating that this copolymer acts on the first baryte nuclei preventing development to larger crystals and keeping them in their 'embryo stage'. In the absence of any organic additive, the baryte precipitation pathway involves the formation of elliptical/spherical nanoparticles ranging from 20 to $150 \mathrm{~nm}$ (Judat and Kind, 2004). Due to the agreement in terms of size, it seems reasonable to propose that the copolymer acts at this stage of the precipitation process, inhibiting the further development of these nuclei. These sizes are in agreement also with particle sizes obtained in AFM experiments when $0.5 \mathrm{ppm}$ of inhibitor was used. Further analysis needs to be carried out to determine if trace amounts of copolymer are actually incorporated into to the initial nuclei.

\section{Conclusions}

The results of in situ AFM observations show that the commercial copolymer (maleic acid/allyl sulfonic acid copolymer with phosphonate groups, partial sodium salt) tested, in concentrations as small as $1 \mathrm{ppm}$, completely blocked baryte-surface growth, probably by adsorption of an inhibitor layer to baryte (001) cleavage surfaces. At lower copolymer concentrations (0.1 ppm and $0.5 \mathrm{ppm}$ ) tested here, this commercial copolymer also has a significant impact on the (001) baryte surface, initially promoting 2D nucleation before inhibiting it. The growth mechanism in the presence of $0.5 \mathrm{ppm}$ inhibitor, observed in AFM experiments, is modified, such that nanoparticle attachment to the surface occurred instead of 2D-island nucleation and spreading. This is probably due to the copolymer stabilizing the nanoparticles.

The effect on 3D nucleation from our conductivity measurements and morphology analysis show that at low $(0.1 \mathrm{ppm}, 0.25 \mathrm{ppm}$ and $0.5 \mathrm{ppm}$ ) concentrations, the inhibitory effect is on growth (Fig. 2) because the number of particles obtained was not reduced (Fig. $3 a, b$ ). At higher inhibitor concentrations, the morphology of baryte crystals changed significantly, with a reduction in size of the particles and the loss of crystallographic form, to give almost spherical particles. This is clear evidence of adsorption of copolymer molecules on the baryte crystal faces, hindering their development and keeping them in the embryo stage.

\section{Acknowledgements}

This research was made possible by a Marie Curie grant from the European Commission in the framework of the MINSC ITN (Initial Training Research network), Project number 290040. 
The authors are grateful to Manuel Prieto and two anonymous reviewers for their constructive comments which helped to improve the overall quality of the paper.

\section{References}

Baynton A., Chandler, B.D., Jones, F., Nealon, G., Ogden, M.I., Radomirovic, T., Shimizu, G.K.H. and Taylor, J.M. (2011) Phosphonate additives do not always inhibit crystallization. CrystEngComm, 13, 1090-1095.

Baynton, A., Ogden, M.I., Raston, C.L. and Jones, F. (2012) Barium sulfate crystallization dependence on upper rim calix[4]arene functional groups. CrystEngComm, 14, 1057-1062.

Benton, W.J., Collins, I.R., Grimsey, I.M., Parkinson, G.M. and Rodger, S.A. (1993) Nucleation, growth and inhibition of barium sulfate-controlled modification with organic and inorganic additives. Faraday Discussions, 95, 281-297.

Blount, C.W. (1977) Barite solubilities and thermodynamic quantities up to $300^{\circ} \mathrm{C}$ and 1400 bars. American Mineralogist, 62, 942-957.

Coveney, P.V., Davey, R., Griffin, J.L.W., He, Y., Hamlin, J.D., Stackhouse, S. and Whiting, A. (2000) A new design strategy for molecular recognition in heterogeneous systems: A universal crystal-face growth inhibitor for barium sulfate. Journal of the American Chemical Society, 122, 11557-11558.

Fernandez-Diaz, L., Putnis, A. and Cumberbatch, T.J. (1990) Barite nucleation kinetics and the effect of additives. European Journal of Mineralogy, 2, 495-501.

Jones, F., Oliveira, A., Rohl, A.L., Parkinson, G.M., Ogden, M.I. and Reyhani, M.M. (2002) Investigation into the effect of phosphonate inhibitors on barium sulfate precipitation. Journal of Crystal Growth, 237-239, 424-429.

Judat, B. and Kind, M. (2004) Morphology and internal structure of barium sulfate - derivation of a new growth mechanism. Journal of Colloid and Interface Science, 269, 341-353.

Kowacz, M., Putnis, C.V. and Putnis, A. (2007) The effect of cation:anion ratio in solution on the mechanism of barite growth at constant supersaturation: Role of the desolvation process on the growth kinetics. Geochimica et Cosmochimica Acta, 71, 5168-5179.

Long, X., Ma, Y., Cho, K.R., Li, D., De Yoreo, J.J. and Qi，L. (2013) Oriented calcite micropillars and prisms formed through aggregation and recrystallization of poly(acrylic acid) stabilized nanoparticles. Crystal Growth and Design, 13, 3856-3863.

Mavredaki, E., Neville, A. and Sorbie, K. (2011) Assessment of barium sulphate formation and inhibition at surfaces with synchrotron X-ray diffraction (SXRD). Applied Surface Science, 257, 4264-4271.

Mavredaki, E., Neville, A. and Sorbie, K.S. (2011) Initial stages of barium sulfate formation at surfaces in the presence of inhibitors. Crystal Growth and Design, 11, 4751-4758.

Parkhurst, D.L. and Appelo, C.A.J. (1999) Users guide to PHREEQC (version 2) - a computer program for speciation, batch reaction, one-dimensional transport, and inverse geochemical calculations. U.S. Geological Survey Water-Resources Investigation Report, 99-4259.

Piana, S., Jones, F. and Gale, J.D. (2006) Assisted desolvation as a key kinetic step for crystal growth. Journal of the American Chemical Society, 128, 13568-13574.

Pina, C.M., Becker, U., Risthaus, P., Bosbach, D. and Putnis, A. (1998) Molecular-scale mechanisms of crystal growth in barite. Nature, 395, 483-486.

Pina, C.M., Putnis, C.V., Becker, U., Biswas, S., Carroll, E.C., Bosbach, D. and Putnis, A. (2004) The inhibition of barite growth by phosphonates: Determination of adsorption isotherms by atomic force microscopy. Surface Science, 553, 61-74.

Putnis, C.V., Kowacz, M. and Putnis, A. (2008) The mechanism and kinetics of DTPA-promoted dissolution of barite. Applied Geochemistry, 23, 2278-2788.

Qi, L., Coelfen, H. and Antonietti, M. (2000) Control of barite morphology by double-hydrophilic block copolymers. Chemistry of Materials, 12, 2392-2403.

Sangwal, K. (1998) Growth kinetics and surface morphology of crystals grown from solutions: recent observations and their interpretations. Progress in Crystal Growth and Characterization of Materials, 36, 163-248.

Shakkthivel, P., Sathiyamoorthi, R. and Vasudevan, T. (2006) Acrylic acid-diphenylamine sulphonic acid copolymer threshold inhibitor for sulphate and carbonate scales in cooling water systems. Desalination, 197, 179-189.

Sorbie, K.S. and Mackay, E.J. (2000) Mixing of injected, connate and aquifer brines in waterflooding and its relevance to oilfield scaling. Journal of Petroleum Science and Engineering, 27, 85-106.

Teng, H.H., Dove, P.M., Orme, C. and De Yoreo, J.J. (1998) Thermodynamics of calcite growth: baseline for understanding biomineral formation. Science, 282, 724-727.

Van der Leeden, M.C. and Van Rosmalen, G.M. (1995) Adsorption behaviour of polyelectrolytes on barium sulfate crystals. Journal of Colloid and Interface Science, 171, 142-149.

Van Rosmalen, G.M. (1983) Scale prevention with special reference to threshold treatment. Chemical Engineering Communications, 20, 209-233. 